\title{
ATZ WORLDWIDE
}

\section{Dear Reader,}

Now in its $114^{\text {th }}$ year of publication, ATZ has lost none of its attractiveness for its users, as I am always pleased to hear and discover for myself. It is required reading for all vehicle technology specialists in their everyday work, and is the number 1 source of information among all the various media on offer. And amazingly, that is the case in more than 50 countries on all continents.

To ensure that more and more Englishspeaking readers can understand our content in full, ATZworldwide was established as an e-magazine a few years ago, and has since acquired a wide readership. This electronic medium contains all of the specialist articles of ATZ in an English language version. In future, even more articles from international automotive development will be added. You can order a sample copy at springervieweg-service@springer.com. I would also be grateful if you would recommend this e-magazine to your colleagues, to enable this instantly accessible specialist medium to become even more popular.

For several years now, our event activities (ATZlive) relating to current issues in our technical field have been successful in networking our readers and bringing them together for a fertile exchange of experiences. I would therefore like to draw your attention to the following events: $12^{\text {th }}$ International ATZ Conference for Body Engineering, 10/11 May 2012 in Hamburg; $3^{\text {rd }}$ International Munich Chassis Symposium, 21/22 June 2012 in Munich; $1^{\text {st }}$ International Conference on Automotive Management, 10/11 July 2012 in Wiesbaden.
I would also like to take this opportunity to encourage you to make regular use of our many and varied online initiatives. ATZonline.de provides you with the very latest news from the automotive industry and you can also subscribe free of charge to our twice weekly newsletter to find more detailed reports. And if you have the time, please join in the discussion at the ATZblog to ensure an even more lively exchange of ideas.

Warm regards,

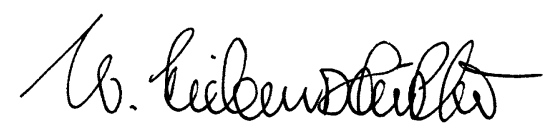

WOLFGANG SIEBENPFEIFFER,

Editor-in-Chief and Editor-in-Charge Stuttgart, March 2012

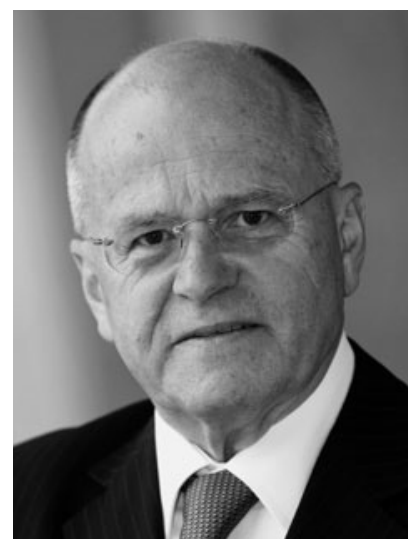

